Original Article (short paper)

\title{
Benefits of physical exercise on Parkinson's disease disorders induced in animal models
}

\author{
Luciana Renata da Conceição1(1), Leandro Pereira de Moura ${ }^{1,2}$, José Rodrigo Pauli1,2® \\ ${ }^{1}$ Universidade Estadual de Campinas, Faculdade de Ciências Aplicadas, Laboratório de Biologia Molecular do \\ Exercício (LABMEX), Limeira, SP, Brasil; ${ }^{2}$ Universidade Estadual de Campinas, Faculdade de Ciências Aplicadas, \\ Programa de Pós-graduação em Ciências da Nutrição e do Esporte e Metabolismo, Limeira, SP, Brasil.
}

\begin{abstract}
Aim: The preventive and therapeutic role of physical exercise in Parkinson's disease (PD) has been the target of study of many scientific groups, and the research often is done in experimental models, especially rodents. Thus, the aim of this review was to analyze a database, elucidating the main benefits that the systematized practice of physical activity/ exercises can contribute to PD in animal models. Method: Based on this question, a search on PubMed and Medline database containing the terms: "Parkinson's disease" AND "animal model" AND "physical exercise" was performed. The most pertinent studies were selected by the criteria year of publication (2009- 2018) and the original article. It was used papers involving animal models and physical exercises, as well as other studies, which allowed an introductory explanation in PD, covering its pathophysiology, and the neurochemical responses of physical exercise in rodents. Results: The results showed that there was a decrease in the levels of nigrostriatal neurodegeneration and an increase in the neuroprotective effect related to the training program. Conclusion: It was concluded that physical exercise has been pointed as an important neuroprotective strategy in animal models of Parkinson's disease, especially those applied at moderate intensities, which were effective in reducing the inflammatory profile, elevating the expression of genes and proteins related to neuronal restoration, mitochondrial biogenesis, repair of the dopaminergic system, besides other events also capable of reflecting improvements in motor and cognitive behavior of animals.
\end{abstract}

Keywords: animal experimentation, dopamine, exercise therapy, neuroinflammation, neuronal degeneration.

\section{Introduction}

Approximately 10 per 100,000 individuals are diagnosed with Parkinson's disease (PD) per year, a chronic illness whose prevalence reaches 100 to 200 persons in the same size and period sampling, thus, it is estimated that approximately $1 \%$ of the world population is affected by $\mathrm{it}^{1}$. In this context, much has been studied about PD, as well as effective therapeutic actions in the disease, with emphasis on physical exercise $\mathrm{e}^{2-5}$.

As a study tool, animal models are quite efficient, since they allow the application of physical exercise protocols, constituting a plausible research strategy. As presenting genetic similarities with humans, they have the advantage of requiring a shorter development time of the programs, allowing direct analysis of brain areas affected by PD. Thus, we consider that this review will help research groups to determine future directions in this area and, more importantly, establish more effective and objective actions regarding the study of the effect of exercise on PD.

This study aimed to conduct a systematic review to identify how physical exercise would benefit Parkinson's disease in animal models.

\section{Materials and Methods}

The systematic review process began in February 2018, with the definition of the guiding question: what are the main benefits of practicing physical exercises in experimental models of Parkinson's disease? It was then conducted according to the structure PRISMA 2009 Cheklist $^{6}$ and considering the SYRCLE guidelines ${ }^{7}$, with the following search expressions: 1- "Parkinson's disease" AND 2- "animal model" AND 3"Physical exercise". Terms such as "parkinsonism" and "Parkinson symptoms" were not included in the search, since there is a possibility of parkinsonian symptoms and parkinsonism are present in other neurological disorders in addition to the PD, and sporadic cases do not appear in Parkinson's disease ${ }^{8}$. In this sense, the term "physical activity" has also not been used because it covers all types of physical movements performed by a body, while "physical exercise" is defined as a specific subcategory of physical activity, planned, structured and repetitive, aiming the improvement or maintenance of one or more components of physical fitness 9 . It was also decided to search only for "animal model" to delimit the use of animals in the studies, because when typed 
synonyms such as "mouse", "rodent", "rat" and / or "mice", the returned articles weren't investigations exclusively involving PD.

The research was conducted in the Laboratory of Molecular Biology of Exercise (LaBMEx), Faculty of Applied Sciences, University of Campinas - Unicamp - Limeira campus, and the literature review was completed in March 2018. We found 285 publications, being excluded the works of revision and studies without a clear description of the substance used for induction of PD. We included only articles that used physical exercises as a therapeutic method, original and rodent works, and finally articles published in the last 10 years (2009-2018); after the inclusion criteria, a total of 10 articles were selected.

\section{Results}

\section{Search Results}

\section{Pathophysiology of Parkinson's disease}

PD is a progressive neurodegenerative disease that triggers motor and non-motor disorders, including rest tremor, muscle stiffness, bradykinesia, postural instability, cognitive dysfunction, and dementia, among others ${ }^{10,11}$, due to the loss of the neurotransmitter dopamine, of a brain region called the substantia

\section{Healthy Brain}

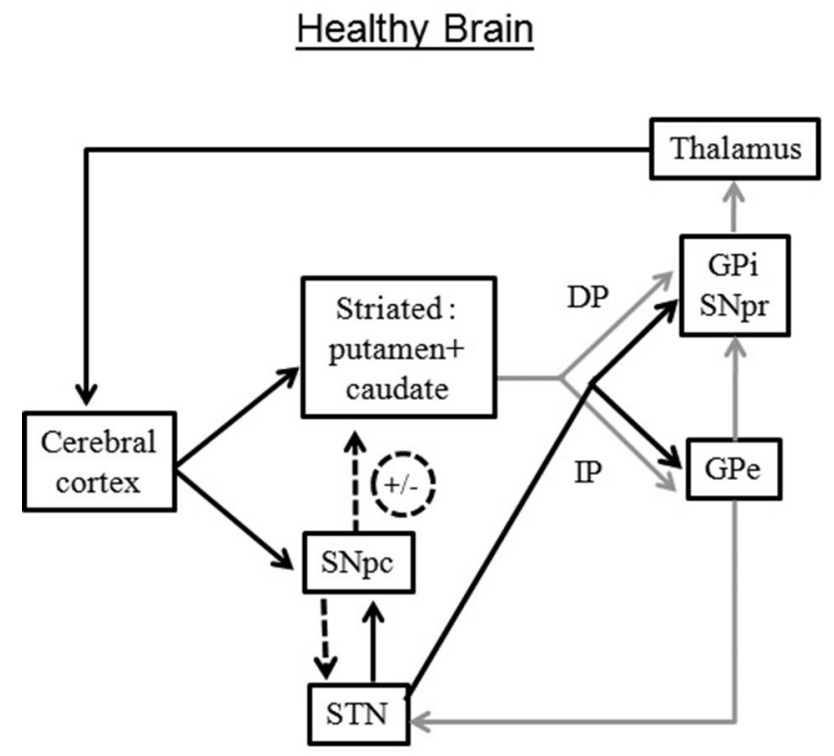

$\stackrel{\text { Glutamate }}{\longrightarrow}$

GABA nigra, located in the basal ganglia $(\mathrm{GB})^{12-14}$, comprising the striatum (caudate nucleus and putamen), the internal and external pallidum globe, subthalamic nucleus (STN), substantia nigra pars compacta $(\mathrm{SNpc})$ and reticulata $(\mathrm{SNpr})$ and the intralaminal nuclei of the thalamus. The cerebral cortex sends excitatory input to the striatum via glutamate (an important neurotransmitter); such input is modulated by nigrostriatal dopamine projections. The striatum, in turn, has dopamine receptors, being more expressed the receptors D1 and D2, where the first trigger excitatory effects, by direct pathway, and the second inhibitory, by indirect pathway. In the direct pathway, estriatofugal neurons mediated by gammaaminobutyric acid (GABA), inhibit the output GB structures, the pale globe inner portion (GPi) and SNpr, which in turn extend GABAergic fibers to the thalamus. In the indirect pathway, axons of striatum neurons connect with the pale globe external portion (GPe) and this leads GABAergic fibers to the STN, which acts by emitting glutamatergic axons for GPi and SNpr; GABAergic fiber communication between GPi / SNpr and GPe also occurs, reciprocally. The glutamatergic thalamic-cortical fibers complete the circuit.

Such pathways, direct and indirect (figure 1) ${ }^{15}$, are responsible for the harmony of motor movements, but, as said before, are mediated by dopamine, which is significantly reduced in Parkinson's disease. It is believed that this deficit in the nigrostestrial projections of dopamine to its receptors compromises the entire pathway of movement control, causing dyskinesias ${ }^{10,16-18}$.

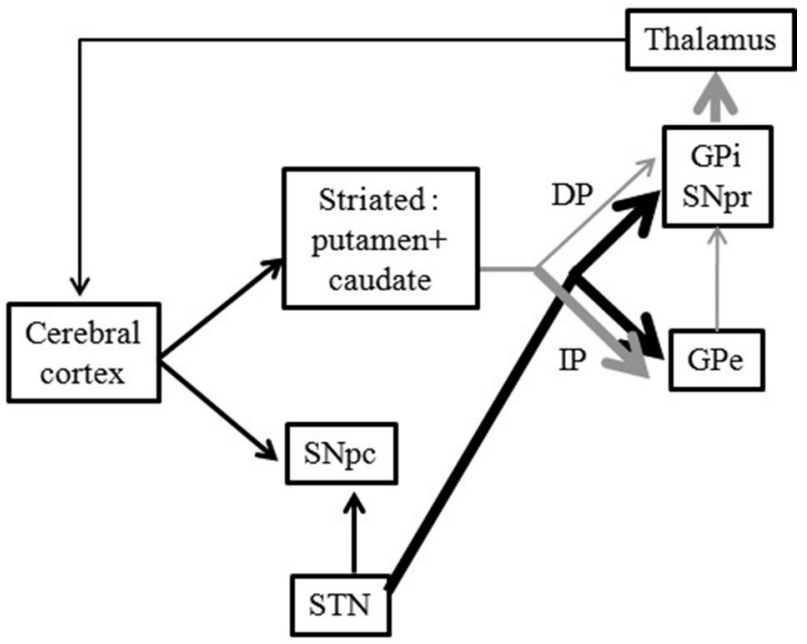

Figure 1. Direct and indirect pathways of the basal ganglia in healthy individual and with PD. Adapted from GOBBI; BARBIERI; VITÓRIO et al., (2014) $)^{18}$.

PD: Parkinson's disease; DP: direct pathway; IP: indirect pathway; SNpc: substantia nigra pars compacta; STN: subthalamic nucleus; GPi: pale globe inner portion; SNpr: substantia nigra pars reticulata; Gpe: pale globe external portion. 
Genetic predispositions allied to environmental factors are considered responsible for cellular alterations that lead to progressive neuronal degeneration. Poewe et al. $(2017)^{19}$ show that social rather than biological causes may be behind the reason why PD is less common in African Americans and Asians in the United States. The same authors state that lifestyle or shared genetic factors may explain these findings, as the incidence of PD is lower among users of caffeine and smokers and higher in individuals exposed to pesticides or who have suffered a traumatic brain injury. The presence of Lewy bodies and neuritis (agglomerates consisting mainly of the $\alpha$-synuclein and ubiquitin proteins) when they arise together in the surviving dopaminergic neurons are the pathological hallmark of $\mathrm{PD}^{20,21}$.

\section{Physical exercise in animal models of Parkinson's disease}

The search for research correlating physical exercises in animal models of PD returned 285 publications, 184 in the electronic database PubMed and 101 in the electronic database Medline (figure 2); included articles published in the last 10 years (2009-2018), totaling 233 papers; of these, we selected those who only worked with animals (208) and excluded duplicate articles (59). Among the 149 remaining articles, we selected those with a detailed description of the drug or substance used for the induction of PD, that used the physical exercise as a therapeutic method, original works and with rodents; after the inclusion criteria, a total of 10 articles were selected (figure 2).

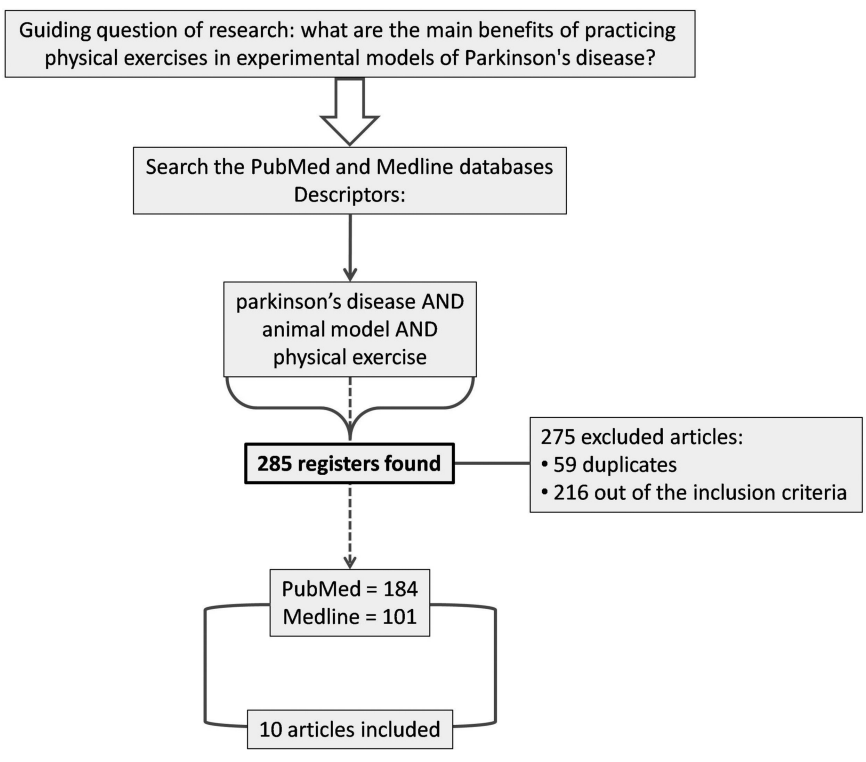

Figure 2. Flow diagram of study.

\section{Neurochemical effects of exercise in animal models of Parkinson's disease}

Physical exercise has been extensively studied and implemented in rehabilitation and treatment programs in people with Parkinson's disease ${ }^{22,23}$. It is a strategy to improve the quality of life of healthy individuals and also with PD, as it contributes to a better functional capacity of the patient ${ }^{24}$. However, much is still being debated about its benefits in the pathophysiology of PD. Some studies propose by what mechanisms physical exercise is capable of promoting important neurochemical alterations in PD models, mainly related to mitochondrial activity, the density of dopaminergic receptors and regulation of neurotrophic factors. Mice that participated in an aerobic training program increased the activities of complex 1 of the respiratory chain of electrons and mitochondrial citrate synthase enzymes, increasing the glycolytic and oxidative activity of these animals, suggesting an increase in mitochondrial biogenesis. There was also an increase in the density and / or number of D2 receptor binding sites for DA in the striatum of these mice compared to the sedentary ones, which decreased; with reduced dopaminergic turnover in the striatum, improved synaptic plasticity and reduced motor damage; physical exercise also reduces apoptosis in models of toxin MPTP (1-methyl-4-phenyl1,2,3,6-tetrahydropyridine) which acts by inhibiting complex 1 of the respiratory chain electron, but accomplishes this inhibition only half of its capacity in trained animals.

The neuroprotective role of physical exercise is mainly due to the increase in the neurotrophic factors BDNF (brainderived neurotrophic factor) and GDNF (glial cell line-derived neurotrophic factor) responsible for the regulation of neuronal survival, differentiation, and synaptic plasticity. Physical exercise raises the levels of proBDNF (BDNF precursor), which is cleaved and generates the mBDNF (mature BDNF) and $\mathrm{mBDNF}$ selectively activates a receptor also overexpressed by physical exercise, TrkB (tyrosine kinase B), triggering a signaling cascade intracellular, culminating in neuronal survival. It is suggested that cleavage of proBDNF is crucial in determining the regulation of brain neurotrophic actions.

Also suggested as responsible for the neuroprotective effect of physical exercise is the negative regulation of the dopamine transporter, DAT, responsible for the uptake of substances such as 6-OHDA (6-hydroxydopamine) and MPTP $^{25-27}$.

\section{Primary Results}

It is possible to have a broader view of some of the benefits that systematized practice of physical exercise can provide (Table 1). 
Table 1. Different types of physical exercises used and the main positive effects on Parkinson's disease.

\begin{tabular}{|c|c|c|c|c|}
\hline Author (s) & $\begin{array}{l}\text { Exercise } \\
\text { protocol }\end{array}$ & Animal & Substance & Main results \\
\hline $\begin{array}{l}\text { Aguiar et al. } \\
(2015)^{27} \text {. }\end{array}$ & $\begin{array}{l}\text { Running on a } \\
\text { treadmill }\end{array}$ & C57BL / 6 mouse & 6-OHDA ${ }^{\mathrm{a}}$ & $\begin{array}{l}\downarrow \text { nigrostriatal neurodegeneration, functional impairment and } \\
\text { supersensitivity of DA }{ }^{\mathrm{b}} \text { receptors } \\
\uparrow \text { expression of genes involved in mitochondrial biogenesis and } \\
\text { enzymatic antioxidant defenses }\end{array}$ \\
\hline Toy et al. $(2014)^{28}$. & Treadmill & C57BLJ / 6 mouse & MPTP $^{c}$ & $\uparrow$ expression of proteins involved in synaptic connectivity \\
\hline $\begin{array}{l}\text { Tuon et al. } \\
(2014)^{25} \text {. }\end{array}$ & $\begin{array}{l}\text { Aerobic or } \\
\text { Strength }\end{array}$ & C57BL / 6 mouse & 6-OHDA ${ }^{\mathrm{a}}$ & $\begin{array}{l}\text { Inhibited depressive conduct and restoration of proBDNF }{ }^{\mathrm{d}}, \mathrm{BDNF}^{\mathrm{e}} \\
\text { and TrkB }{ }^{\mathrm{f}} \text { levels in the striatum and hippocampus }\end{array}$ \\
\hline $\begin{array}{l}\text { Kintz et al. } \\
(2013)^{29}\end{array}$ & $\begin{array}{l}\text { Running on a } \\
\text { treadmill }\end{array}$ & $\begin{array}{l}\text { Transgenic Drd2- } \\
\text { eGFP-BAC mouse }\end{array}$ & МРТР & $\begin{array}{l}\text { Restoration of GluA2 } 2^{\mathrm{g}} \text { expression, } \downarrow \text { GluA } 1^{\mathrm{h}} \text { expression on the cell } \\
\text { surface, selectively in D2R-MSNs }{ }^{\mathrm{i}}\end{array}$ \\
\hline $\begin{array}{l}\text { Landers et al. } \\
(2013)^{30} \text {. }\end{array}$ & $\begin{array}{l}\text { Forced or } \\
\text { voluntary aerobic }\end{array}$ & $\begin{array}{l}\text { Long Evans } \\
\text { Mouse }\end{array}$ & 6-OHDA ${ }^{\mathrm{a}}$ & $\begin{array}{l}\text { Non-expressive results in voluntary exercise when compared to the } \\
\text { forced exercise, resembling the group not exercised }\end{array}$ \\
\hline Real et al. $(2013)^{31}$. & Treadmill & Wistar Rat & 6-OHDA ${ }^{\mathrm{a}}$ & $\begin{array}{l}\text { Improvement of the dopaminergic system and recovery of motor } \\
\text { behavior. Beneficial effects of exercise appear to involve the } \\
\text { BDNF-TrkB system neuroprotective way. }\end{array}$ \\
\hline $\begin{array}{l}\text { Wang et al. } \\
(2013)^{32} \text {. }\end{array}$ & $\begin{array}{l}\text { Aerobic exercise } \\
\text { forced }\end{array}$ & $\begin{array}{l}\text { Sprague-Dawley } \\
\text { Rat }\end{array}$ & 6-OHDA ${ }^{\mathrm{a}}$ & $\begin{array}{l}\text { Functional reorganization in the basal ganglia-thalamo-cortical } \\
\text { circuit and of the regions participating in the cerebellum-thalamic- } \\
\text { cortical circuit; activation of the dorsal striatum, } \downarrow \text { hyperemia of the } \\
\text { uncertain zone; } \uparrow \text { activation with the mesolimbic circuit. }\end{array}$ \\
\hline Lau et al. $(2011)^{33}$. & $\begin{array}{l}\text { Running on a } \\
\text { treadmill }\end{array}$ & C57BL / 6 mouse & $\mathrm{MPTP}^{\mathrm{c}}$ & $\begin{array}{l}\text { Neuroprotective effect; } \uparrow \text { balance; } \downarrow \text { mitochondrial dysfunction; } \\
\text { restoration of mitochondrial respiration; } \uparrow \text { in the endogenous } \\
\text { level of BDNF } \text { and GDNF }{ }^{\mathrm{j}} \text { in the substantia nigra and striatum; } \\
\text { promotion of neurotrophic activity in nigrostriatal neurons. }\end{array}$ \\
\hline $\begin{array}{l}\text { Gerecke et al. } \\
(2010)^{34} \text {. }\end{array}$ & $\begin{array}{l}\text { Spontaneous } \\
\text { running Wheel }\end{array}$ & C57BL / 6J mouse & $\mathrm{MPTP}^{\mathrm{c}}$ & $\begin{array}{l}\text { Neuroprotective effects in animals with higher activity time in the } \\
\text { running wheel }\end{array}$ \\
\hline $\begin{array}{l}\text { Vučković et al. } \\
(2010)^{35} \text {. }\end{array}$ & $\begin{array}{l}\text { Running on a } \\
\text { treadmill }\end{array}$ & C57BL / 6 mouse & $\mathrm{MPTP}^{\mathrm{c}}$ & $\begin{array}{l}\text { Intensive racing on a treadmill facilitates neuroplasticity by } \uparrow \\
\text { expression of DA-D } 2 \mathrm{Rs}^{\mathrm{k}} \text { in the striatum. }\end{array}$ \\
\hline
\end{tabular}

a6-hydroxydopamine; bdopamine; ${ }^{\mathrm{a}} 1$-methyl-4-phenyl-1,2,3,6-tetrahydropyridine; ${ }^{\mathrm{d}}$ derived neurotrophic factor precursor of the brain; ebrain-derived neurotrophic factor; ${ }^{\mathrm{f}}$ tropomyosin kinase B receptor (BDNF receptor); AMPAR, alpha-amino-3-hydroxy-5-methyl-4-

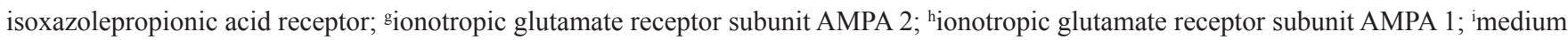
spindle neuron of the striatopalidal; ${ }^{\text {g }}$ glial cell line derived neurotrophic factor; ${ }^{k}$ dopamine receptor 2 ; $\uparrow$, increase; $\downarrow$ decrease.

\section{Discussion}

Training on a horizontal treadmill, 5 days per week, with rest at weekends, totaling 6 weeks of training, where the animals were placed on the treadmill at the initial speed of $16 \mathrm{~m} / \mathrm{min}$. increasing every 3 minutes with a further $2 \mathrm{~m} / \mathrm{min}$. until the mouse reaches exhaustion ${ }^{27}$ or starting at a speed of $10 \mathrm{~m} / \mathrm{min}^{28,29,35}$ showed that the groups exercised were more resistant to PD phenotypes, reducing the loss of $\mathrm{TH}$ (tyrosine hydroxylase) from $\mathrm{SNpc}$ and striatum and increasing functional capacity in these animals ${ }^{27-29,35}$. There was also a reduction in the latency at the beginning of the training among the exercised animals, as well as an increase in the density of medium spiny neurons (MSN) and dendritic column in I and II subunits of dopamine receptors (DA-D1R- and DA-D2R) of these rats. They found that the protocol provided benefits related to motor skills learning and performance in the DA-exhausted state ${ }^{28}$. Besides, the exercise restored: the relative expression of GluA1 (glutamate receptor subunit I) to GluA2 (glutamate receptor II subunit), the Selective Rectification Index on the D2R-MSNs and the long-term depression (LTD) on dorsolateral $\mathrm{MSNs}^{29}$ while the treadmill training intensified improved motor behavior and increased striated DA-D2R. These results were found from models created as follows: $4 \mu \mathrm{g} 6-\mathrm{OHDA}$ per 4 weeks ${ }^{27} ; 80 \mathrm{mg}$ / kg MPTP per 42 days $^{28,29}$ or 49 days after the induction of the disease $\mathrm{e}^{35}$.

The BDNF neurotrophin and its TrkB receptor were reduced in the brains of animals treated with 6-OHDA (twice the dose used in the previous study: $8 \mu \mathrm{g}$ of 6-OHDA, but for only 8 days); however, such changes were significantly attenuated in animals exercised aerobically or anaerobically before induction of the disease. However, there was no difference in the levels of these proteins when compared to the group that underwent aerobic training (treadmill running / 50 min. per day / 13-17 $\mathrm{m} \mathrm{min}^{-1}$, with a rest interval of 48 hours/for 8 weeks) with the group submitted to strength training (stair climbing / 40-50 min. per day / $50 \%$ load until reaching $100 \%$ of body weight at the end of 8 weeks, with a 48 -hour interval between training sessions $)^{25}$.

To verify if there are differences in the capacity of neuroprotection between forced training and voluntary exercise, a forced exercise program was carried out for 6 weeks, 5 days per week, 2 sessions of $15 \mathrm{~min}$. a day on a treadmill at a speed of $8 \mathrm{~m} / \mathrm{min}$. in the first two weeks and in the subsequent weeks the velocity was $15 \mathrm{~m} / \mathrm{min}$. The voluntary exercise group was housed in cages with running wheels bearing account turns. They verified that the animals of the voluntary group ran more than the forced group, but the second group performed better in the 
behavioral asymmetry test. However, the six-week pre-injury

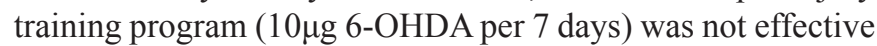
in producing neuroprotective effects in injured animals ${ }^{30}$.

On exercise-induced neuroprotection, animals were divided into two main groups: (1) K252a (BDNF receptor blocker) injection, and (2) no blockade of this receptor. These groups were randomized into another four: control, sedentary, exercised 3 days per week for four weeks before and four weeks after induction of PD and exercised 3 per week for four weeks after induction of PD ( 2 injections $3 \mu \mathrm{g}$ of 6-OHDAper 4 weeks). The training was carried out on a treadmill at a speed of $10 \mathrm{~m} / \mathrm{min}$. for 40 min. It was found that sedentary groups showed a reduction in BDNF levels as compared with trained groups. In addition to decreasing TH of SNpc and striated in both sedentary groups, especially in the group that received K252a injection than in the sedentary group, demonstrating the potential neuroprotector of physical exercise ${ }^{31}$.

Rats underwent forced jogging with incremental velocity and duration of 4 weeks, 5 days per week for 20 minutes per session after 6-OHDA injury (4 injections of $10 \mu \mathrm{g}$ per 4 weeks) showed better behavior, noting that exercise may lead to an increase in overall cerebellar circuit recruitment cortical, as well as causing functional alterations of the mesolimbic system and significant reductions in relative cerebral blood flow $(\mathrm{rCBF})$ in the frontal / prefrontal cortex ${ }^{32}$.

Exercises on the treadmill, with speed starting at $6 \mathrm{~m} / \mathrm{min}$. up to $15 \mathrm{~m} / \mathrm{min}$., 5 days per week, $40 \mathrm{~min}$. per session for 18 weeks resulted in recovery of TH content and total TH-positive cell number in SNpc, and long-term resistance exercises (18 weeks) had a neuroprotective potential to restore nigrostriatal DA function in chronic PD with neurodegeneration moderate, whereas neural recovery was not evident with short-term exercise ( 10 weeks) ( 10 doses MPTP $-15 \mathrm{mg} / \mathrm{kg} /$ injection s.c. per 5 week schedule with an interval of 3.5 days between injections $)^{33}$.

Finally, animals trained for 1,2 or 3 months prior to induction of $\mathrm{PD}$, in a voluntary running wheel, presented positive alteration of important proteins in the energy regulating and cellular metabolic pathways, such as ubiquinone, Echs 1 and ApoA1; the main results were found among the group trained for 3 months $(80 \mathrm{mg} / \mathrm{kg} \text { MPTP per } 7 \text { days })^{34}$.

Therefore, it is possible to observe that the dose and the time of administration of the drug to induce Parkinson's disease is variable between the studies. Besides, it was verified that of the 10 studies performed, 7 studies used a training protocol with a progressive intensity of effort ${ }^{25,27-30,32,34}$. Only 3 of these studies did not have progressive increases of intensity during the experiment $t^{31,33,34}$. These results indicate that the intensity of exercise is relevant against Parkinson disease symptoms (motor and cognitive disorders). This demonstrates that the development of a physical exercise program by an exercise physiologist is relevant to obtained satisfactory results.

Furthermore, it may be considered that it is not yet fully established whether exercise by itself or its combination with some kind of drug is responsible for the positive effects at both central and peripheral level (e.g.: skeletal muscle) on Parkinson's disease. However, through the studies, it is observed that the accomplishment of physical training protocols performed at moderate intensity, has effect in providing GDNF increase at the central level, a hormone that has been postulated like "factor of survival", it means that it has protective action against substances that are harmful to dopaminergic neurons ${ }^{33}$. The presence of GDNF in dopaminergic neurons induces an increase in the size, in the dendrites and axons in these cells $\mathrm{s}^{33}$. Therefore, physical training would be able to stimulate plasticity in the brain and spinal cord and even with an important action on neurogenesis. As a result, improvement in behavioral results and sensory-motor responses in animals with the induction of Parkinson's disease is observed. Thus, the neuroprotective effects of physical exercise help preventively against the degeneration process of neurons in the central nervous system and consequently preventively against Parkinson's disease.

In addition to the effects on neurons and at the central level, physical exercise is also capable of improving the oxidative capacity on skeletal muscles ${ }^{27,31,33}$. This effect is related to the capacity that physical exercise exerts on the regulation of mitochondrial biogenesis in the skeletal muscle. By increasing the number of mitochondria, physical training allows the body to become more able to consume energy, making it difficult to accumulate excess intramuscular fat, preventing the inflammatory process and consequently, metabolic side effects such as insulin resistance ${ }^{27,33,34}$. In addition to the increased mitochondrial density, physical training can make the process of beta-oxidation more efficient and, thus, the muscle becomes more resistant to fatigue ${ }^{34}$. This has implications in locomotor capacity and performing motor activities and, therefore, it implies in the improvement of the motor performance and also in the central nervous system.

Therefore, the actions in both the skeletal muscle and in the central level, obtained through physical exercise, influence the improvement of the quality of life in the organism affected by Parkinson's disease.

\section{Conclusion}

It can be considered that most of the studies were carried out using aerobic physical exercise protocols, especially with running on a treadmill and of moderate intensity, which exposes the need for more researches to be performed with resistance exercises, since the only one article cited in this text found positive responses similar to the aerobic exercise protocol. Also, it seems that regardless of the type of exercise, the intensity factor influences significantly and induces the most favorable changes on PD-related dysfunctions, and it is suggested that moderate intensities are more effective in attenuating the commonly observed changes in PD induction in animal models if compared to lighter exercises.

\section{References}

1. World Health Organization (WHO). Neurological Disorders: public health challenges. Geneva: WHO Document Production Services; 2006. 232 p. 
2. Alberts JL, Linder SM, Penko AL, Lowe MJ, Phillips M. It is not about the bike, it is about the pedaling: forced exercise and Parkinson's disease. Exerc Sport Sci Rev 2011; 39: 177-186.

3. Konerth M, Childers J. Exercise: A possible adjunct therapy to alleviate early Parkinson disease. JAAPA 2013; 26: 30-3.

4. Frazzitta G, Maestri R, Ghilardi MF, Riboldazzi G, Perini M, Bertotti $\mathrm{G}$, et al. Intensive rehabilitation increases BDNF serum levels in parkinsonian patients: a randomized study. Neurorehabil Neural Repair 2014; 28: 163-8.

5. Tajiri N, Yasuhara T, Shingo T, Kondo A, Yuan W, Kadota T, et al. Exercise exerts neuroprotective effects on Parkinson's disease model of rats. Brain Res 2010; 1310: 200-7.

6. Liberati A, Altman DG, Tetzlaff J, Mulrow C, Gøtzsche PC, Ioannidis JP, et al. The PRISMA Statement for Reporting Systematic Reviews and Meta-Analyses of Studies That Evaluate Health Care Interventions: Explanation and Elaboration. PLoS Med 2009; 6: 1-28.

7. Vries RBM, Hooijmans CR, Langendam MW, van Luijk J, Leenaars M, Ritskes-Hoitinga M, et al. A protocol format for the preparation, registration and publication of systematic reviews of animal intervention studies. Evid Based Preclin Med 2015; 2: 1-9.

8. Christine CW, Aminoff MJ. Clinical differentiation of parkinsonian syndromes: Prognostic and therapeutic relevance. Am J Med 2004; 117: 412-9.

9. Caspersen CJ, Powell KE, Christenson GM. Physical Activity, Exercise, and Physical Fitness: Definitions and Distinctions for Health-Related Research. Public Health Rep 1985; 100: 126-131.

10. Heumann R, Moratalla R, Herrero MT, Chakrabarty K, Drucker-Colín R, Garcia-Montes JR, et al. Dyskinesia in Parkinson's Disease - mechanisms and current non-pharmacological interventions. J Neurochem 2014; 130: 472-489.

11. Sutachan JJ, Casas Z, Albarracin SL, Stab BR, Samudio I, Gonzalez J, Morales L, Barreto GE. Cellular and molecular mechanisms of antioxidants in Parkinson's disease. Nutr Neurosci 2012; 15: 120-6.

12. Picconi B, Piccoli G, Calabresi P. Synaptic Dysfunction in Parkinson's Disease. Adv Exp Med Biol 2012; 970: 553-572.

13. More SV, Kumar H, Kim IS, Song SY, Choi DK. Cellular and Molecular Mediators of Neuroinflammation in the Pathogenesis of Parkinson's Disease. Mediators Inflamm 2013; 952375: 1-12.

14. Tansey MG, McCoy MK, Frank-Cannon TC. Neuroinflammatory mechanisms in Parkinson's disease: Potential environmental triggers, pathways, and targets for early therapeutic intervention. Exp Neurol 2007; 208: 1-25.

15. Álvarez AMA, Gallego ICR, Gómez S, Suárez-Escudero JC. Núcleo pedúnculo pontino, y su relación con la fisiopatología de la Enfermedad de Parkinson. Acta Neurol Colomb 2013; 29 : 180-190.

16. Huot P, Johnston TH, Koprich JB, Fox SH, Brotchie JM. The Pharmacology of L-DOPA-Induced Dyskinesia inParkinson's Disease. Pharmacol Ver 2013; 65: 171-222.

17. Herrera CRM. El núcleo subtalámico en la fisiopatología de la enfermedad de Parkinson y su rol como diana quirúrgica. Rev Chil Neuro-Psiquiat 2011; 49: 62-8.

18. Gobbi LTB, Barbieri FA, Vitório R, editors. Doença de Parkinson e exercício físico. Ed. Curitiba, CRV, 2014.
19. Poewe W, Seppi K, Tanner CM, Halliday GM, Brundin P, Volkmann J, et al. Parkinson disease. Nat. Rev. Dis. Primers 2017; 3: 1-21.

20. Trancikova A, Tsika E, Moore DJ. Mitochondrial Dysfunctionin Genetic Animal Models of Parkinson's Disease. Antioxid Redox Signal 2012; 16: 896-919.

21. Aron L, Klein R. Repairing the parkinsonian brain with neurotrophic factors. Trends Neurosci 2011; 34: 88-100.

22. Dashtipour K, Johnson E, Kani C, Kani K, Hadi E, Ghamsary M, Pezeshkian S, Chen JJ. Effect of exercise on motor and nonmotor symptoms of Parkinson's disease. Parkinsons Dis 2015; 586378: 1-5.

23. Šumec R, Filip P, Sheardová K, Bareš M. Psychological benefits of nonpharmacological methods aimed for improving balance in Parkinson's disease: asystematic review. Behav Neurol 2015; 620674: 1-16.

24. Tanaka K, Quadros Junior AC, Santos RF, Stella F, Gobbi LTB, Gobbi S. Benefits of physical exercise on executive functions in older people with Parkinson's disease. Brain and Cognition 2009; 69: 435-441.

25. Tuon T, Valvassori SS, Dal Pont GC, Paganini CS, Pozzi BG, Luciano TF, et al. Physical training prevents depressive symptoms and a decrease in brain-derived neurotrophic factor in Parkinson's disease. Brain Res Bull 2014; 108: 106-112.

26. Petzinger GM, Fisher BE, McEwen S, Beeler JA, Walsh JP, Jakowe MW. Exercise-enhanced neuroplasticity targeting motor and cognitive circuitry in Parkinson's disease. Lancet Neurol 2013; 12: 716-726.

27. Aguiar Junior A S, Duzzioni M, Remor A P, Tristão FS, Matheus FC, Raisman-Vozari R, et al. Moderate-intensity physical exercise protects against experimental 6-hydroxydopamine-induced hemiparkinsonism through Nrf2-antioxidant response element pathway. Neurochem Res 2015; 41: 64-72.

28. Toy WA, Petzinger GM, Leyshon BJ, Akopian GK, Walsh JP, Hoffman MV, et al. Treadmill exercise reverses dendritic spine loss in direct and indirect striatal medium spiny neurons in the 1-methyl-4- phenyl-1,2,3,6-tetrahydropyridine (MPTP) mouse model of Parkinson's disease. Neurobiol Dis 2014; 63: 201-9.

29. Kintz N, Petzinger G M, Akopian G, Ptasnik S, Williams C, Jakowec MW, et al. Exercise modifies $\alpha$-amino-3-hydroxy-5-methyl-4-isoxazolepropionic acid receptor expression in striatopallidal neurons in the 1-methyl-4-phenyl-1,2,3,6-tetrahydropyridine-lesioned mouse. J Neurosci Res 2013; 91: 1492-1507.

30. Landers MR, Kinney JW, Allen DN, Breukelen F. A comparison of voluntary and forced exercise in protecting against behavioral asymmetry in a juvenile hemiparkinsonian rat model. Behav Brain Res 2013; 248: 121-8.

31. Real CC, Ferreira AFB, Chaves-Kirsten GP, Torrão AS, Pires RS, Brito LRG. BDNF receptor blockade hinders the beneficial effects of exercise in a rat model of Parkinson's disease. Neuroscience 2013; 237: 118-129.

32. Wang Z, Myers KG, Guo Y, Ocampo MA, Pang RD, Jakowec MW, et al. Functional Reorganization of Motor and Limbic Circuits after Exercise Training in a Rat Model of Bilateral Parkinsonism. PLoS One 2013; 8: 1-18. 
33. Lau YS, Patki G, Das-Panja K, Le WD, Ahmad SO. Neuroprotective effects and mechanisms of exercise in a chronic mouse model of Parkinson's disease with moderate neurodegeneration. Eur J Neurosci 2011; 33: 1264-1274.

34. Gerecke KM, Jiao Y, Pani A, Pagala V, Smeyne RJ. Exercise Protects Against MPTP-Induced Neurotoxicity in Mice. Brain Res 2010; 1341C: 72-83.

35. Vučković MG, Li Q, Fisher B, Nacca A, Leahy RM, Walsh JP, et al. Exercise elevates dopamine D2 receptor in a mouse model of Parkinson's disease: in vivo imaging with [18F] fallypride. Mov Disord 2010; 25: 2777-2784.

\section{Corresponding author}

Luciana Renata da Conceição

Faculty of Applied Sciences of Unicamp, Laboratory of Molecular Biology

Email: lucianarenatac@yahoo.com.br

Manuscript received on February 28, 2019

Manuscript accepted on June 18, 2019

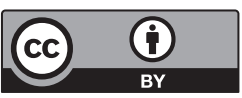

Motriz. The Journal of Physical Education. UNESP. Rio Claro, SP, Brazil - eISSN: 1980-6574 - under a license Creative Commons - Version 4.0 